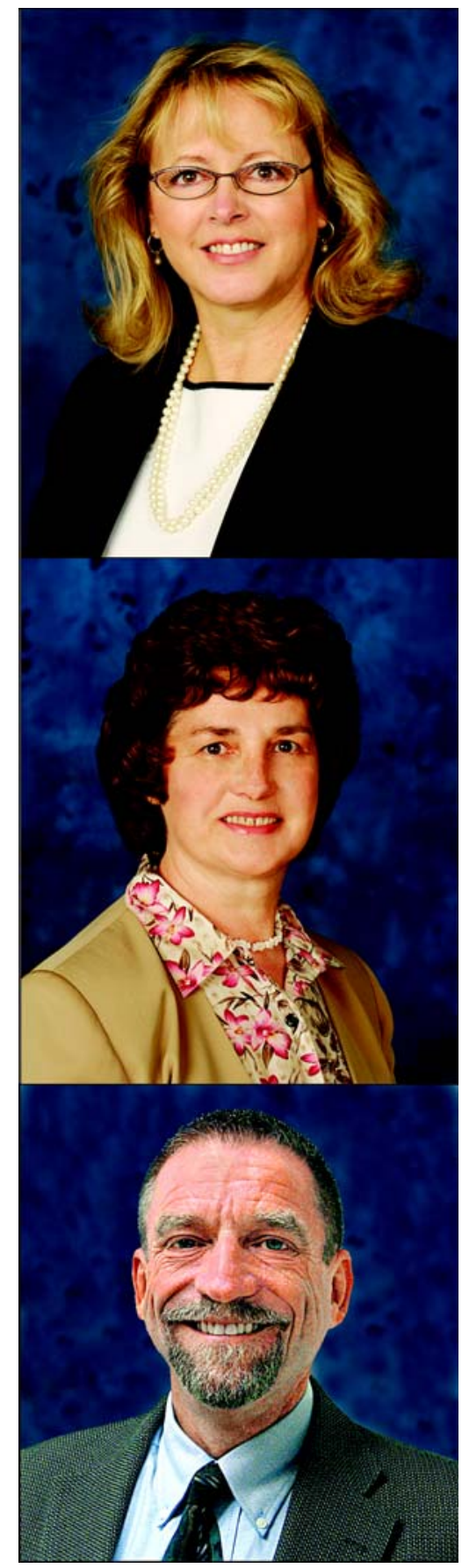

Christine Elnitsky, PhD, RN; Martha Bryan, EdD; Robert D. Kerns, PhD

\section{Veterans Health Administration's pain research portfolio and publications}

\section{INTRODUCTION}

The Veterans Health Administration (VHA) aims to honor America's veterans by providing exceptional healthcare that improves their health and wellbeing. To accomplish this mission, VHA will continuously improve the quality and safety of healthcare for veterans - particularly in health areas associated with their military service-and conduct research and development in clinical and system improvement areas. Approximately 5 million people received care in Department of Veterans Affairs (VA) healthcare facilities in 2006. The VA healthcare system includes settings across the healthcare continuum, including 156 hospitals, 877 outpatient clinics, 136 nursing homes, 43 residential rehabilitation facilities, and 207 readjustment counseling centers. The majority of patients, approximately 54 million, were treated in outpatient clinics.

The VA Office of Research and Development (ORD) is dedicated to the discovery of new knowledge, the creation of innovations to advance healthcare for veterans and the nation, and the development of VA researchers and healthcare leaders. In 2006, funding for VA research from all sources was just over $\$ 1.5$ billion. The VA currently conducts more than 10,000 research projects at more than $100 \mathrm{VA}$ medical centers.

VA research is organized into four services of research and development (R\&D): Clinical Science, Health Services, Rehabilitation, and Biomedical Laboratory. Within ORD, pain-relevant research is broadly defined and is supported within each of these programs. A brief summary of the research focus and priorities of each research service portfolio follows.

Clinical Science R\&D focuses on clinical research on intact human beings. The program funds population-based research, including efficacy and effectiveness trials on veterans' health issues and epidemiological and technological studies. Priorities related to pain in this portfolio include aging research; studies on the mechanisms and mediators of pain treatments; efficacy studies of innovative treatment approaches, including psychological interventions and complementary and alternative medicine interventions; and studies of pain in the context of terminal illness and palliative care. Health Services R\&D focuses on all areas of healthcare delivery system organization, resources, processes, patient population, healthcare use, and outcomes. These studies include topics of healthcare quality, access, patient outcomes, costs, and cost-effectiveness. Priorities related to pain in this portfolio include deployment health studies, studies of racial and ethnic diversity and disparities, examination of patientprovider interactions, and development and evaluation of innovative methods for promoting improved pain assessment and management. Within this last priority, studies of pain assessment and management of individuals with cognitive impairments have been a particularly important focus. Rehabilitation R\&D 
focuses on preventing and minimizing disability and restoring functional independence in veterans with disabilities. Priorities in this portfolio include deployment health-related pain initiatives; the efficacy of innovative rehabilitation approaches to pain management; development and evaluation of pain outcome assessment methods, especially those involving technology; and pain and psychiatric comorbidities. Finally, Biomedical Laboratory R\&D focuses on basic biological or physiological principles using laboratory and animal models. Funded studies include animal models and investigations of tissues, blood, or other biological specimens from humans. Pain-related priorities in the portfolio include studies with a neurological and cellular-level focus and basic research with potential to contribute to the development of innovative pain treatments.

Initiatives established across all research service portfolios provide foci for a broad cross-section of pain dimensions. The recent and continuing focus on deployment health issues for veterans returning from Operation Iraqi Freedom (OIF) and Operation Enduring Freedom (OEF) represents a particularly important area for targeted solicitations that emphasize pain management. In these cases, the focus is often on improved treatments for deployment-related pain associated with chronic conditions, traumatic injuries, burns and amputation, unexplained pain, and neurological injuries. The Nursing Research Initiative has provided an alternative mechanism for funding research by nurse investigators. Many of these studies focus on clinical topics related to assessing and managing pain and evaluating clinical practice guidelines for pain management. Recently, the Rehabilitation and Health Services R\&D Services jointly sponsored a request for proposals on topics related to amputation and prosthetics outcomes. The recently funded Polytrauma and Blast-Related Injuries Quality Enhancement Research Initiative (PT/BRI-QuERI) center aims to improve quality, outcomes, and efficiency of care and is also jointly sponsored by the Rehabilitation and Health Services R\&D Services. This PT/ BRI-QuERI will explicitly encourage the development of a focused research agenda related to pain management. Finally, a significant proportion of other ORD-funded research centers have developed a focus on pain, and VA anticipates that this emphasis will continue to expand over the next several years.

Another important context in which to consider VA's pain-relevant research agenda is the VHA National Pain Management Strategy initiated in 1998 by the Undersecretary for Health at that time, Dr. Kenneth Kizer. Among the several primary goals of this initiative was an explicit emphasis on promoting pain-relevant research [1]. One of the key charges to the multidisciplinary National Pain Management Strategy Coordinating Committee was "identifying research opportunities and priorities in pain management and facilitating collaborative research efforts" [1, p. 2]. In response, a Pain Research Working Group (PRWG) was established. To date, more than 50 scientists and scholars have been engaged as members of the PRWG. The majority of members are investigators employed by VA. Most members are currently funded through ORD and/or other Federal and private sources for a program of pain-relevant research, and most others are actively involved as co-investigators on funded projects or in unfunded research in this area. Representatives from ORD have also continued to serve an important liaison role. Interests of the members are highly varied and span many key areas of pain and pain management. Most are involved in clinically relevant, applied, and health services research, although a few members are actively involved in more basic research. A central goal of the PRWG is to encourage and support initiatives within VHA ORD designed to encourage research on pain and pain management, and we expect that the PRWG will continue to emerge as an important resource for ORD as it develops its pain-relevant research agenda.

\section{METHODS}

We used two sources of information to describe the pain research portfolio in the VA. First, we reviewed administrative databases of all four research services detailing research projects funded recently or currently by the respective VA services. Second, we surveyed VA pain experts. We surveyed two groups: members of the multidisciplinary National Pain Management Strategy Coordinating Committee and VA employee members of the PRWG. Citations and 
abstracts for pain-relevant, peer-reviewed publications from these experts were solicited and reviewed.

We identified pain topics being pursued by VA researchers in ORD-funded studies by analyzing the portfolio analysis of projects funded as of March 2005 and March 2007. Administrative databases of all four research services were reviewed for pain and pain-related studies funded by the VA. We identified a preliminary list of research topics through an inductive analysis using the research titles and abstracts in the administrative databases. We then used this list to classify research topics in the priority areas related to pain. Topics were classified into eight categories and their frequency analyzed. When projects contained more than one topic or issue, we selected the most prominent one.

We identified peer-reviewed publications on topics of pain research through survey of the Coordinating Committee and PRWG members in December 2005 to January 2006. The 13 members of the Coordinating Committee include one education specialist, four nurses, two pharmacists, four physicians, and two psychologists. Of the 51 PRWG members, 42 were employed by the VA and were surveyed, including the 6 psychologist and physician members of the Coordinating Committee. The remaining members of the PRWG represented the disciplines of epidemiology, medicine, nursing, pharmacy, psychology, and sociology. Members came from 24 different VA facilities, including several ORD-funded research centers, as well as the VA Central Office.

Members surveyed described their pain-relevant research interests quite broadly. Among the stated interests were those related to specific painful conditions, including osteoarthritis, musculoskeletal pain, spinal cord injury, burns, amputations, traumatic injuries, and irritable bowel syndrome; pain and psychiatric comorbidities, including depression, posttraumatic stress disorder (PTSD), and substance abuse; pain and medical comorbidities, including cardiovascular disease; factors associated with pain management decision making; diversity issues in pain and pain management, including disparities in pain treatment; decision support systems to improve treatment of pain; psychological interventions for chronic pain; mechanisms underlying chronic pain; mechanisms of psychological treatment efficacy; pain and dementia; pain among elderly persons; implementation of pain management guidelines; telehealth applications; complementary and alternative medicine approaches to pain management; pain and palliative care; outcomes assessment; issues related to the use of opioids in pain management, including opioid pharmacokinetics, addiction, effects on functioning, and the efficacy of buprenorphine for chronic pain management; collaborative models of care; pain management in specific clinical settings, including critical care settings, emergency departments, long-term care settings, and primary care settings; pain among female veterans; and postdeployment pain.

\section{RESULTS}

\section{ORD-Funded Research}

Two categories of materials characterized our research: a review of administrative records and a review of published literature by VA pain researchers. ORD administrative databases were surveyed and revealed research studies on various dimensions of pain. During content analysis, we reduced the topic categories to eight different, but overlapping, pain-related dimensions of the funded research study abstracts and titles. The frequency of topics funded in separate studies in March 2005 and in March 2007, along with the categorization, is presented in the Table. The category of "mechanisms" was added in March 2007 to better account for a significant proportion of funded studies in this broad domain.

The results of this review reveal several apparent trends in the VA's pain research portfolio. Most important is a 27 percent increase in the number of ORD-funded pain-relevant studies from early 2005 to March 2007. Not surprisingly, the largest proportion of funded studies is attributed to the Rehabilitation R\&D Service and is largely accounted for by this program's recent solicitation for chronic pain and pain management studies. During the time period examined, the Rehabilitation R\&D Service funding of painrelevant research projects increased from 10 to 16 funded projects, or an increase of 60 percent! During the same period, the number of funded pain-relevant projects also increased in the Clinical Science and Biomedical Laboratory R\&D Services. Importantly, 
JRRD, Volume 44, Number 2, 2007

Table.

Frequency of pain-related studies, by topic, in Department of Veterans Affairs Research and Development (R\&D) Services.

\begin{tabular}{|c|c|c|c|}
\hline Topic & $\begin{array}{c}\text { Service } \\
(2005 / 2007)\end{array}$ & $\begin{array}{c}\text { Total } \\
(2005 / 2007)\end{array}$ & $\begin{array}{l}\text { Percentage } \\
(2005 / 2007)\end{array}$ \\
\hline $\begin{array}{l}\text { Deployment-health-related education of veterans and care } \\
\text { providers, assessment, treatment, epidemiology and measurement, } \\
\text { and pain mechanisms }\end{array}$ & $\begin{array}{l}\operatorname{HSRD}(6 / 1) \\
\operatorname{RRD}(1 / 1) \\
\operatorname{CSRD}(0 / 4) \\
\operatorname{BLRD}(4 / 0)\end{array}$ & $11 / 6$ & $26 / 13$ \\
\hline $\begin{array}{l}\text { Pain management and Clinical Practice Guideline translation, } \\
\text { including decision support, exercise and nutrition program, } \\
\text { effectiveness in rehabilitation, and self management }\end{array}$ & $\begin{array}{l}\operatorname{HSRD}(6 / 5) \\
\operatorname{RRD}(2 / 1) \\
\operatorname{CSRD}(0 / 0) \\
\operatorname{BLRD}(1 / 0)\end{array}$ & $9 / 6$ & $21 / 13$ \\
\hline $\begin{array}{l}\text { Treatment of chronic pain or musculoskeletal pain, including } \\
\text { antidepressants, opiates, endomorphins, self-management, } \\
\text { cognitive-behavioral therapy, gene therapy, treatment of chronic } \\
\text { pain and PTSD, neural stimulation, and electrotherapy }\end{array}$ & $\begin{array}{l}\operatorname{HSRD}(1 / 2) \\
\operatorname{RRD}(5 / 8) \\
\operatorname{CSRD}(2 / 2) \\
\operatorname{BLRD}(0 / 0)\end{array}$ & $8 / 12$ & $19 / 26$ \\
\hline $\begin{array}{l}\text { Neuropathic pain, including nociception, peripheral neuropathy, } \\
\text { and spinal cord injury }\end{array}$ & $\begin{array}{l}\operatorname{HSRD}(0 / 0) \\
\operatorname{RRD}(0 / 1) \\
\operatorname{CSRD}(0 / 0) \\
\operatorname{BLRD}(3 / 3)\end{array}$ & $3 / 4$ & $7 / 9$ \\
\hline Disparities & $\begin{array}{l}\operatorname{HSRD}(1 / 1) \\
\operatorname{RRD}(0 / 0) \\
\operatorname{CSRD}(0 / 0) \\
\operatorname{BLRD}(0 / 0)\end{array}$ & $1 / 1$ & $2 / 2$ \\
\hline
\end{tabular}

during this same period, the Health Services R\&D Service funded multiple studies on postdeployment health and related problems specifically associated with new veterans from Iraq and Afghanistan, and although not specifically documented in the present survey, a review of the abstracts clearly shows that several of these recently funded Health Services projects include at least a secondary focus on pain care.

ORD funding for pain-relevant research is distributed across a wide array of content areas. Not surprisingly, given the VHA commitment to funding studies with relatively direct implications for policy and practice related to the care of veterans, the largest proportion of funded projects target investigations of pain interventions, including both pharmacological and nonpharmacological treatments and rehabilitation approaches. Another large category of funded projects is in the domain of clinical assessment. Many of these clinically relevant studies target conditions directly related to deployment health, including a significant proportion that focus on neuropathic pain conditions, spinal cord injuries, and musculoskeletal pain conditions. Laboratory and clinical investigations of pain mechanisms are another particularly important focus of investigation, representing 23 percent of the total ORD pain-relevant portfolio. 


\section{Peer-Reviewed Publications}

The survey of the Coordinating Committee and PRWG members requested that investigators send a list of citations for original, peer-reviewed, and painrelevant publications from the most recent 5 years (since 2001) to the third author. Accounting for the overlap of Coordinating Committee and PRWG members, we surveyed a total of 42 investigators. Responses were received from 20 (48\%) of the surveyed investigators. A total of 134 citations for published reports were received.

In general, the citations for peer-reviewed and published journal articles represented the various disciplines and diverse array of interests of the surveyed investigators. The most commonly reported topics were related to opioid use in the management of pain, including laboratory studies of mechanisms of action and efficacy and clinical studies of opioid dependence and chronic pain; the management of arthritis, especially investigations of ethnic and racial differences in osteoarthritis management and treatment response; studies of pain in elderly persons; development and evaluation of novel approaches to pain assessment, including measurement of pain treatment outcome and psychological factors; studies of pain coping; investigations of pain and coprevalent psychiatric conditions, particularly depression, PTSD, and substance abuse; epidemiological and descriptive studies of pain and pain-related disability among veterans seeking care in VA primary-care settings; investigations of the efficacy of biofeedback and other complementary and alternative medicine approaches to pain management; laboratory studies of spinal pain mechanisms; laboratory and human studies of hyperalgesia; investigations of the efficacy of various injection therapies; studies of motivational factors in self-management approaches to chronic pain, including specific investigations of the concept of readiness to change; and studies of pain among women.

We noted a significant confound between the sample of responding investigators, the number of publications reported per respondent, and the topics or themes of the research focus. That is, a relatively small number of responding investigators accounted for a large proportion of the citations. This fact significantly skewed the overall focus of the research topics of the published reports in the direction of these investigators' interests. Nine investigators reported 101 published articles.

A significant proportion of the reported publications focused specifically on veteran samples. Several articles provide important data on the prevalence and nature of pain and pain-related disability among samples of veterans receiving care in the VHA [2-9]. Haskell et al. recently documented a particularly high prevalence of pain among women veterans receiving care in a VA women's clinic [10].

VA investigators continue to examine a broad array of important questions related to chronic pain and pain management via studies that rely primarily on veteran samples for data collection. Results of these studies are often significant in terms of their implications for clinical practice and health policy, not only for the VHA, but also for the broader healthcare delivery system. Studies by Clark et al. have reported on pain treatment outcome measures that were specifically developed and normed on veteran samples [11]. Several investigators have examined the role of psychological factors in the management of persistent pain among veteran samples [12-14]. Trafton, Ilgen, and their colleagues reported on a series of studies that investigated the role of persistent pain as a moderator of effective treatment for opioiddependent veterans [15-17]. Predictors of chronic widespread pain among veterans of the first Gulf War have been identified as family history of unexplained symptoms, predeployment symptoms, and level of perceived stress [18]. Results of a VHA Cooperative Study designed to examine the effects of cognitivebehavioral therapy and aerobic exercise on Gulf War veterans' illnesses, a complex problem that includes the presence of diffuse musculoskeletal pain, have also been reported [19]. Buffum et al. examined the effectiveness of acetaminophen delivered on a fixed interval versus as-needed for pain in a sample of veterans residing in nursing home settings [20].

Published articles have specifically reported on the VHA National Pain Management Strategy. Members of the Coordinating Committee and others have published several articles that provide updates on the accomplishments related to the Strategy [21-23]. Results of the VHA/Institute for Healthcare Improvement project documented the ability to achieve rapid improvement in pain management during a 9-month 
period of intensive performance improvement efforts across 72 VA facilities [24]. Recently, Mularski et al. examined the effects of the VHA "Pain as the 5th Vital Sign” Initiative [25].

Perhaps not surprisingly, few articles reported on samples of service members returning from deployment during OEF and OIF. Two published articles by the same group of investigators provide much needed data on the prevalence and nature of pain complaints among this group of veterans and highlight the need for greater attention to this emerging problem [26-27].

\section{DISCUSSION}

Our primary objective was to examine the portfolio of pain-relevant research funded by ORD, as well as original peer-reviewed publications of VA investigators that focus on pain and pain management, to identify common themes and potential gaps in the current research activities of VA investigators and scholars. Our review revealed the breadth of the VA pain research portfolio, which spans basic laboratory research to applied and epidemiological research that may have direct or indirect relevance for clinical practice and policy. The review emphasizes ORD's strong commitment to advancing the science of pain and pain management. This commitment is consistent with the VHA National Pain Management Strategy that emphasizes the important role of basic and applied investigation in the area of pain to promote improved pain management for veterans served by the VHA, as well as the broader population with acute and persistent pain and pain at the end of life.

Recent military actions have specifically encouraged increased attention to issues of deployment health and specific problems of increasing prevalence among service members, including polytrauma, burns, blast injuries, and amputations. Consistent with this increased focus, ORD has recently published targeted solicitations in these areas, and for the most part, these solicitations have specifically incorporated attention to pain and pain management. These solicitations have been successful in yielding many fundable research projects, including several that have incorporated a primary or secondary focus on pain. The success of these targeted solicitations in producing fundable projects is highlighted by our review that documents that this research theme has the largest number of funded projects and that funding for projects in this area has substantially increased in the past 2 years. Not surprisingly, publications related to these targeted solicitations have been few to date, but results of ongoing projects certainly will be published in the next several years, contributing important information that can enhance our understanding of such problems as posttraumatic pain and neuropathic pain, as well as the pain care of veterans with these problems.

The next several themes identified through inspection of the ORD research portfolio are those representing a strong clinical and applied emphasis. Numerous research projects were identified that focus on fostering translation, dissemination, and improved practice consistent with the latest research findings. Another cluster of funded research projects focuses on randomized controlled trials of novel pharmacological, psychological, and rehabilitation approaches to pain management. Another clinical theme identified focuses on methods of improving pain assessment, including particularly important clinical issues for the care of veteran subgroups, such as those with significant cognitive impairments and frank dementia and elderly veterans in long-term care settings. Specific attention to the development and evaluation of painrelevant outcome measures was also identified as an important theme.

For the most part, analysis of the data from the survey of VA investigators' published research during the past 5 years reveals concordance with the themes represented in the ORD-funded projects. A range of clinical topics was represented among the reported publications. Numerous publications reported on the clinical trial results of both pharmacological and nonpharmacological interventions, including studies of populations of particular relevance to the VA healthcare system, such as persons with arthritis and elderly persons. Innovative investigations of biofeedback and complementary and alternative medicine interventions were also reported. Reports on the development and 
psychometric evaluation of pain assessment methods were also well represented among the reported publications. Other topics of particular clinical relevance were included, especially research focused on issues related to opioid use in the management of persistent pain; examinations of racial and ethnic differences and disparities in pain care; and epidemiological and clinical studies of pain and psychiatric comorbidities, especially depression, PTSD, and substance abuse. A significant proportion of the published research reported on basic laboratory science investigations on topics such as mechanisms of action of pharmaceuticals and mechanisms of hyperalgesia.

As already noted, the one exception to the general concordance noted between ORD-funded projects and peer-reviewed publications is in the area of postdeployment health. This particularly important focus of the VA's research agenda is expected to lead to important publishable findings in the next several years and beyond. ORD's funding of research with direct and indirect relevance for practice and policy promises to yield findings that are critical to the VA's efforts to promote optimal pain care for returning OEF/OIF service members.

\section{CONCLUSIONS}

The goal of this review was to identify themes of recently VA ORD-funded projects and publications attributable to this funding. The review documented ORD's strong commitment to conducting quality pain research that spans basic science, health services, rehabilitation, and clinical science domains. Publications similarly represent these domains. The extensive ORD pain-relevant research portfolio is consistent with the VHA National Pain Management Strategy and efforts to promote improved pain care for veterans. Recently funded projects on painful medical conditions related to recent deployment in OEF and OIF will likely soon yield important publishable findings that can be useful in informing further investigation, policy, and practice.

\section{ACKNOWLEDGMENT}

We acknowledge the following portfolio managers in VA's ORD for their contributions to the portfolio analysis: Denise Burton, PhD; Theresa Gleason, PhD; William Goldberg, PhD; and Joseph Webster, PhD.

\section{REFERENCES}

1. Veterans Health Administration. VHA directive 2003-021: Pain management. Washington (DC): Department of Veterans Affairs; 2003.

2. Barry LC, Guo Z, Kerns RD, Duong BD, Reid MC. Functional self-efficacy and pain-related disability among older veterans with chronic pain in a primary care setting. Pain. 2003;104(1-2):131-37.

[PMID: 12855322]

3. Crosby FE, Colestro J, Ventura MR, Graham K. Survey of pain among veterans in Western New York. Pain Manag Nurs. 2006;7(1):12-22. [PMID: 16490732]

4. Dominick KL, Golightly YM, Jackson GL. Arthritis prevalence and symptoms among US non-veterans, veterans, and veterans receiving Department of Veterans Affairs Healthcare. J Rheumatol. 2006;33(2):348-54. [PMID: 16465668]

5. Gironda RJ, Clark ME, Neugaard B, Nelson A. Upper limb pain in a national sample of veterans with paraplegia. J Spinal Cord Med. 2004;27(2):120-27. [PMID: 15162882]

6. Golightly YM, Dominick KL. Racial variations on self-reported osteoarthritis symptom severity among veterans. Aging Clin Exp Res. 2005;17(4):264-69. [PMID: 16285190]

7. Kerns RD, Otis J, Rosenberg RM, Reid MC. Veterans' reports of pain and associations with ratings of health, health-risk behaviors, affective distress, and use of the healthcare system. J Rehabil Res Dev. 2003; 40(5):371-79. [PMID: 15080222]

8. Reid MC, Crone KT, Otis J, Kerns RD. Differences in pain-related characteristics among younger and older veterans receiving primary care. Pain Med. 2002;3(2): 102-7. [PMID: 15102156]

9. Reid MC, Guo Z, Towle VR, Kerns RD, Concato J. Pain-related disability among older male veterans receiving primary care. J Gerontol A Biol Sci Med Sci. 2002;57(11):M727-32. [PMID: 12403801] 
10. Haskell SG, Heapy A, Reid MC, Papas RK, Kerns $\mathrm{RD}$. The prevalence and age-related characteristics of pain in a sample of women veterans receiving primary care. J Womens Health (Larchmt). 2006;15(7): 862-69. [PMID: 16999642]

11. Clark ME, Gironda RJ, Young RW. Development and validation of the Pain Outcomes QuestionnaireVA. J Rehabil Res Dev. 2003;40(5):381-95. [PMID: 15080223]

12. Heapy A, Otis J, Marcus KS, Frantsve LM, Janke EA, Shulman M, Bellmore W, Kerns RD. Intersession coping skill practice mediates the relationship between readiness for self-management treatment and treatment outcome. Pain. 2005;118(3):360-68. [PMID: 16289803]

13. Lombardo ER, Tan G, Jensen MP, Anderson KO. Anger management style and associations with selfefficacy and pain in male veterans. J Pain. 2005; 6(11);765-70. [PMID: 16275601]

14. Carmody TP. Psychosocial subgroups, coping, and chronic low-back pain. J Clin Psychol Med Settings. 2001;8(3):137-48.

15. Trafton JA, Minkel JD, Humphreys K. Determining effective methadone doses for individual opioiddependent patients. PLoS Med. 2006;3(3):e80. [PMID: 16448216]

16. Ilgen MA, Trafton JA, Humphreys K. Response to methadone maintenance treatment of opioid dependent patients with and without significant pain. Drug Alcohol Depend. 2006;82(3):187-93. [PMID: 16219429]

17. Trafton JA, Oliva EM, Horst DA, Minkel JD, Humphreys K. Treatment needs associated with pain in substance use disorder patients: Implications for concurrent treatment. Drug Alcohol Depend. 2004;73(1): 23-31. [PMID: 14687956$]$

18. Ang DC, Peloso PM, Woolson RF, Kroenke K, Doebbeling BN. Predictors of incident chronic widespread pain among veterans following the first Gulf War. Clin J Pain. 2006;22(6):554-63. [PMID: 16788343]

19. Donta ST, Clauw DJ, Engel CC Jr, Guarino P, Peduzzi P, Williams DA, Skinner JS, Barkhuizen A, Taylor T, Kazis LE, Sogg S, Hunt SC, Dougherty CM, Richardson RD, Kunkel C, Rodriguez W, Alicea, Chiliade P, Ryan M, Gray GC, Lutwick L, Norwood D, Smith S, Everson M, Blackburn W, Martin W, Griffiss JM, Cooper R, Renner E, Schmitt J, McMurtry C, Thakore M, Mori D, Kerns R, Park M, Pullman-Mooar S, Bernstein J, Hershberger P, Salisbury DC, Feussner JR. VA Cooperative Study 470 Study Group. Cognitive behavioral therapy and aerobic exercise for Gulf War Veter- ans' illnesses: A randomized controlled trial. JAMA. 2003;289(11):1396-1404. [PMID: 12636462]

20. Buffum MD, Sands L, Miaskowski C, Brod M, Washburn A. A clinical trial of the effectiveness of regularly scheduled versus as-needed administration of acetaminophen in the management of discomfort in older adults with dementia. J Am Geriatr Soc. 2004;52(7):1093-97. [PMID: 15209646]

21. Craine M, Kerns RD. Pain management improvement strategies in the Veterans Health Administration. APS Bull. 2003;13(5):1-9.

22. Kerns RD. Improving pain management in the VA. Fed Pract. 2001;Suppl (August):18-22.

23. Kerns RD, Booss J, Bryan M, Clark ME, Drake AC, Gallagher RM, Green-Rashad B, Markham R, Rosenberg JM, Turner A. Veterans Health Administration National Pain Management Strategy: Update and future directions. APS Bull. 2006;16(1):1-15.

24. Cleeland CS, Reyes-Gibby CC, Schall M, Nolan K, Paice J, Rosenberg JM, Tollett JH, Kerns RD. Rapid improvement in pain management: The Veterans Health Administration and the Institute for Healthcare Improvement Collaborative. Clin J Pain. 2003; 19(5):298-305. [PMID: 12966255$]$

25. Mularski RA, White-Chu F, Overbay D, Miller L, Asch SM, Ganzini L. Measuring pain as the 5th vital sign does not improve quality of pain management. J Gen Intern Med. 2006;21(6):607-12. [PMID: 16808744]

26. Clark ME. Post-deployment pain: A need for rapid detection and intervention. Pain Med. 2004;5(4): 333-34. [PMID: 15563318$]$

27. Gironda RJ, Clark ME, Massengale JP, Walker RL. Pain among veterans of Operations Enduring Freedom and Iraqi Freedom. Pain Med. 2006;7(4):339-43. [PMID: 16898945]

\section{Christine Elnitsky, PhD, RN; ${ }^{1}$ Martha Bryan, EdD; ${ }^{2}$ Robert D. Kerns, $\mathrm{PhD}^{3-5^{*}}$}

${ }^{1}$ Office of Policy, Planning and Preparedness, VA, Washington, DC; ${ }^{2}$ Health Services R\&D Service, VHA, Washington, DC; ${ }^{3}$ Psychology Service, VA Connecticut Healthcare System, West Haven, CT; ${ }^{4}$ National Pain Management Program, VA Central Office, Washington, DC; ${ }^{5}$ Department of Psychiatry, Neurology, and Psychology, Yale University, New Haven, CT

\section{*Email: Robert.Kerns@va.gov}

DOI: 10.1682/JRRD.2007.04.0056 